Vol: 03, Pg:50-51, Yr:2022

\title{
Malaria Control: A New Idea
}

\author{
Biswadeep Chaudhuri \\ Corresponding: biswadeep.chaudhuri@uem.edu.in
}

\begin{abstract}
Since past decades Malaria control has become a big issue for almost every developed citied mainly in India. In this short communication a novel idea has been discussed to control over mosquitoes. Since it has been very difficult to control over all unwanted water bodies, it is therefore easy to keep them with some special additives added into this water that will kill musquitoes at the same time does not effect any aquatic essential life stocks.
\end{abstract}

Keywords: Malaria, Mosquitoes, Herbal oil

\section{Introduction:}

A herbal oil made up of various plant extracts like lemon grass, ginger, cardamom etc. can be used to mix it directly into the water that home various fishes cultivated commercially. This extract will not hamper fishes but will produce a slight smell that will keep away mosquitoes and they will not like to lay eggs there. As a result, mosquito population would be reduced due to lack of reproduction. Such plant extract can be spread using a garden sprayer or using a helicopter if applied in a large area.

\section{Methods:}

Plant extracts (lemon grass, ginger, cardamom etc.) will be dried and grinded well. Therefore they will be boiled for $1 \mathrm{hr}$. and cooled at RT. Now this solution will be mixed with tap water (1:10 ratio) and will be sprayed directly on the mosquito prone water/land surface. It has been shown that if this is done three days repeatedly, mosquitoes will not lay eggs in such water for coming 15-20 days.

\section{Importance:}

In this technique, there is no environmental loss. No pollution is being spread to the mother nature. Fishes will also survive. Moreover the antimicrobial propertied of such herbs will reduce the water born diseases to the fishes. So there will be overall benefit for such method. 


\section{Biodegradability:}

The plant extracts will gradually be degraded by the nature and will be utilized by the aquatic plants without causing any harm to the environment. Environmental safety is not hampered in such a practice.

\section{Conclusion:}

The plant based non-toxic mosquito repellent can be successfully used both in rural and urban areas. Even if this solution come in contact to the plants or other animals, there will be no harm on them. The mode of action is via smell that is not liked by the mosquitoes. Therefore breeding ground of mosquitoes can be restricted and as a result population of mosquitoes can be controlled along with malaria.

\section{References:}

1. Abdulelah, H., Zainal-Abidin, B., In vivo anti-malarial tests of Nigella sativa (Black Seed) different extracts. Am. J. Pharmacol. Toxicol. 2, 46-50. 2007.

2. Azas, N., Laurencin, N., Delmas, F., Di, G.C., Gasquet, M., Laget, M., Timon-David, P., Synergistic in vitro antimalarial activity of plant extracts used as traditional herbal remedies in Mali. Parasitol. Res. 88, 165-171. 2002.

3. Al-Adhroey, A.H., Nor, Z.M., Al-Mekhlafi, H.M., Mahmud, R. Ethnobotanical study on some Malaysian anti-malarial plants: a community-based survey. J. Ethnopharmacol. 132, 362-364. 2010.

4. Ali, A.A.N., Al-rahwi, K., Lindequist, U., Some medicinal plants used in Yemeni herbal medicine to treat malaria. Afr. J. Tradit. Complement. Altern. Med. 1, 72-76. 2004.

5. Ampomah, P., Yankson, K., Akotoye, H.K., Ameyaw, E.O., An ethnomedicinal survey of plants used to treat malaria in the Central Region of Ghana. J. Phytopharmacol. 6, 107-114, 2017. 